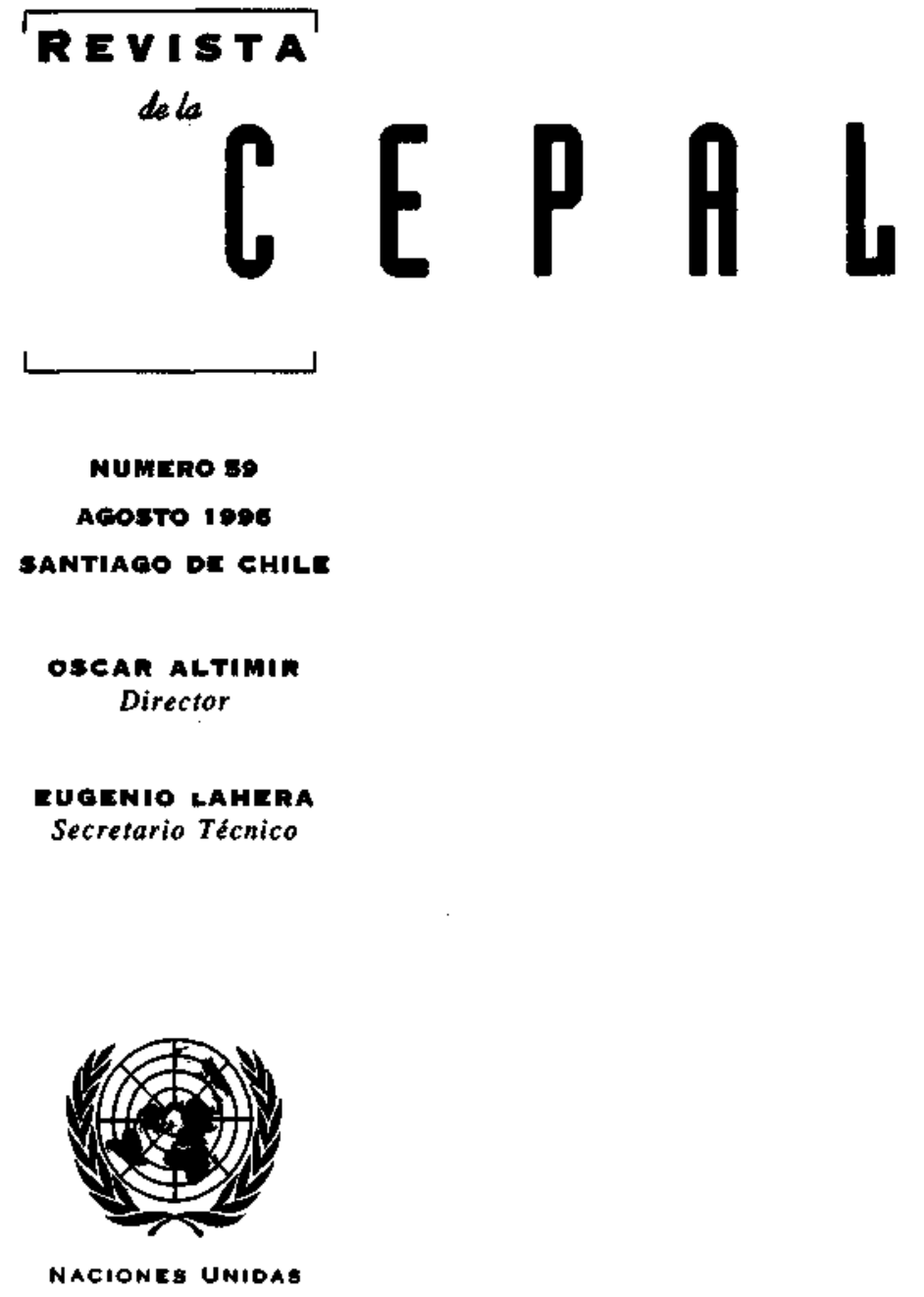


Interacciones entre macro y microeconomía

Gert Rosenthat

Politica económica, instituciones y desarrollo productivo en América Latina

Osvaldo Rosales

Competitividad sistémica: nuevo desafío para las empresas y la política

Klaus Esser, Wolfgang Hillebrand, Dirk Messner y Jörg Meyer-Stamer

La formación de habilidades báslcas y la capacitación para el trabajo productivo

Guillermo Labarca

Los fondos de inversión social en América Latina

Gabriel Siri

Mercados de derechos de agua: componentes institucionales

Miguel Solanes

Los países del Caribe y el área de libre comercio de las Amérlcas

Trevor Harker, Sidya Ould El-Hadj y Lucio Vinhas De Souza

La experiencia argentina: ¿desarrollo o sucesión de burbujas?

Hugo Nochteff

Posibilidades y límites de la reforma en la gestión de

la salud en Chile

Ana Sojo

Orientaciones para los colaboradores de la Revista de la CEPAL 


\section{Los fondos de}

\section{inversión social \\ en América Latina}

\section{Gabriel Siri \\ Ex Director de la Subsede de la CEPAL en México}

En el presente artículo se examinan diversos aspectos relacionados con los fondos de inversión social, en especial aquellos de su financiamiento y la sustentabilidad de los proyectos resultantes, y el papel de los fondos en relación con los ministerios y la autoridad política. También se examina la vinculación entre los fondos y las organizaciones no gubernamentales y el papel que desempeña la cooperación externa. Los fondos de inversion social se crearon para mitigar la pobreza y aminorar los efectos de las políticas de ajuste de los años ochenta. Han demostrado ser mecanismos efícaces para canalizar las corrientes de financiamiento externo y concretarlas en proyectos. La estrategia principal para transferir recursos a los pobres ha consistido en crear empleos transitorios mediante la realización de obras de infraestructura social y económica, así como de proyectos destinados a satisfacer necesidades básicas. Una proporción menor del financiamiento se ha orientado hacia actividades directamente productivas, habitualmente por conducto de organizaciones no gubernamentales. En general, los fondos de inversión social efectivamente han servido para aliviar la pobreza. Aunque no fueron concebidos para hacer frente a los problemas estructurales que la causan, sí han hecho posible atender a agudos problemas económicos y sociales. 


\section{I}

\section{La aparición de los fondos de inversión social}

Alarmados por el aumento de la pobreza en sus países y por las repercusiones sociales de las políticas de estabilización y ajuste estructural aplicadas a fines de los años ochenta, muchos gobiernos latinoamericanos se vieron impulsados a crear fondos de inversión social de emergencia para paliar la pobreza y amortiguar los efectos de las medidas de austeridad adoptadas por el gobierno. Los fondos constituyen un mecanismo nuevo para la acción estatal en este campo, que reúne bajo un solo alero el financiamiento y la promoción de proyectos y la obtención del apoyo financiero de organizaciones extranjeras y países amigos. El primero de estos fondos, el Fondo Social de Emergencia de Bolivia, fue creado en noviembre de 1986 y ejercio gran influencia en la estructura institucional y operativa de los que se establecieron posteriormente en otros países.

Los fondos de inversión social han resultado ser vías adecuadas para convertir las corrientes de financiamiento externo en proyectos concretos. La estrategia principal para transferir recursos a los pobres ha consistido en crear empleos transitorios mediante la ejecución y gestión de proyectos de infraestructura social y económica y de satisfacción de las necesidades básicas. Además, los propios proyectos, en especial las obras de infraestructura, se han concebido de manera de que proporcionen beneficios a largo plazo a las comunidades pobres. Una pequeña proporción del financiamiento disponible se ha canalizado hacia proyectos directamente productivos, por lo general utilizando como intermediarias a organizaciones no gubernamentales.

Los fondos son instituciones autónomas. Exceptuados por ley de la mayoría de las trabas burocráticas ordinarias relacionadas con las contrataciones y las adquisiciones, han podido adoptar métodos de trabajo más dinámicos, propios del sector privado, $y$ han funcionado paralela pero independientemente de los ministerios sectoriales pertinentes. A menudo existe la impresión de que las burocracias estatales están empantanadas en formalismos administrativos y que son

드 El artículo se basa en un estudio elaborado para el Organismo Sueco de Desarrollo Internacional (osol). Las opiniones que en él se expresan son de exclusiva responsabilidad del autor. incapaces de organizar una actividad vasta y eficiente para desembolsar rápidamente los recursos de los proyectos. Los fondos han tenido la suerte de poder conseguir administradores muy preparados y han reunido equipos de trabajo competentes que han centrado sus esfuerzos en los resultados y han hecho lo posible por alcanzar los objetivos propuestos.

Los fondos de inversión social han sido concebidos como intermediarios financieros cuyo objetivo primordial es evaluar y supervisar los proyectos. El diseño y la ejecución de éstos se entrega al sector privado y a los ministerios pertinentes. La cartera de proyectos se determina de acuerdo con las solicitudes de las comunidades y de las organizaciones no gubernamentales o, en algunos casos, por los organismos estatales. Para estimular la selección de proyectos que favorecen a los pobres, así como la transparencia de las operaciones, se han establecido sistemas de información y de gestión basados en criterios técnicos.

Pese a que en un comienzo se pensó que los fondos debían ser transitorios, la tendencia ha sido prolongarles la vida. Varios ya se han convertido en instituciones de inversión de carácter permanente. Algunos de ellos se encuentran aún en las primeras etapas de funcionamiento, pero están buscando formas de asegurar su permanencia.

Atendiendo a las necesidades y a las solicitudes de los países, los donantes externos ${ }^{\natural}$ y las instituciones financieras han cumplido una función catalizadora en la creación y la orientación de los fondos de inversión social y en el suministro de recursos para su funcionamiento. La amplia cooperación que han prestado ha sido de carácter no comercial. Por lo general, el financiamiento otorgado por los bancos internacionales de desarrollo ha adoptado la forma de préstamos en condiciones de favor, mientras que la cooperación prestada por los países donantes y por los organismos de las Naciones Unidas ha consistido principalmente en subvenciones.

El Banco Mundial ha sido financista principal y promotor activo de estas iniciativas. Es justo señalar

\footnotetext{
'Alemania, la Agencia de los Estados Unidos para el Desarrollo Internacional (USAID), el Canadá, la Comunidad Economica Europea, los Países Bajos, el Reino Unido, Suecia y Suiza, entre otros..
} 
también que el marco conceptual y operativo original, concebido por los fundadores del Fondo Social de Emergencia de Bolivia, fue confirmado y perfeccionado en el curso de las primeras conversaciones con el Banco Mundial. Además, el Banco ha mostrado bastante flexibilidad para experimentar con nuevos modelos de préstamos para proyectos, por ejemplo, suministrando recursos para crear empleos transitorios y aplicando procedimientos de adquisición menos rígidos.

El Banco Interamericano de Desarrollo (BID) también ha sido uno de los financistas principales de los fondos de inversión social en América Latina, cuyo diseño lleva la impronta de la institución. La Agencia de los Estados Unidos para el Desarrollo Internacional (USAID) también ha prestado importante apoyo financiero a varios fondos latinoamericanos. En algunos casos, la Agencia ha sido decisiva para la puesta en marcha de las actividades y la orientación de sus prioridades. Por su parte, el Programa de las Naciones Unidas para el Desarrollo (PNUD) ha suministrado financiamiento para cooperación técnica a dichos fondos en casi todos los países latinoamericanos y ha influido mucho en la creación de estas instituciones en Centroamérica.

En definitiva, los fondos de inversión social han demostrado ser una medida acertada para paliar la pobreza. Aunque no resuelven de plano el problema de la pobreza estructural, ciertamente valen más que desentenderse del principal problema económico y social de los países de la región. Hay que reconocer que los que idearon los fondos no pretendieron encontrar una solución óptima basada en el análisis de las causas históricas de la pobreza en la región, sino que adoptaron más bien un criterio pragmático para ver qué resultados inmediatos podrían obtenerse en las actuales circunstancias en algunos de los países más pobres de América Latina.

Los fondos de inversión social pueden servir de enlace entre las organizaciones financieras extranjeras, los gobiernos y las comunidades. Pueden contribuir a que las estrategias de desarrollo y las directrices normativas de los gobiernos se traduzcan en aplicaciones concretas en los planos regional y local. Mediante sus contactos con las organizaciones no gubernamentales y con otras organizaciones de base, los fondos pueden ayudar al desarrollo de proyectos que tengan en cuenta las necesidades reales de los pobres; han demostrado ser capaces de establecer relaciones de trabajo con las organizaciones comunitarias, relaciones que conducen a proyectos ventajosos; tienden a ajustarse mejor a los intereses de los donantes y de los financistas externos, y pueden disipar los temores de que los recursos no se utilicen eficazmente, haciendo hincapié en la transparencia de las operaciones financieras. Aunque por desgracia los fondos a menudo no han desempeñado este papel fundamental, en la medida de sus posibilidades pueden representar a los gobiernos y a los países donantes y organizaciones financieras internacionales ante las comunidades, y a la inversa.

\section{II}

\section{Avances e interrogantes}

\section{Insuficiencia de los fondos}

Téricamente, los fondos de emergencia se crearon para compensar a los pobres la carga que les imponían los programas de estabilización y ajuste estructural. En la práctica, no se ha perseguido este objetivo y los fondos no han sido más que un mecanismo para aliviar momentáneamente a algunos de los pobres. En realidad, por lo general ni siquiera se han determinado qué efectos ha tenido en sus ingresos la merma del empleo y de los salarios reales. La compensación no tiene vínculo directo con las personas afectadas, ni con las necesidades concretas (trabajo, alimentación, etc.).

Lo anterior no quiere decir que se hayan derrochado los recursos. En los países en que la gran mayoría de la población es pobre, todos los programas sociales benefician a algunas de las personas necesitadas. Por lo demás, cuando son muchos los que han sido pobres por varias generaciones, la prioridad que debería haberse dado a los nuevos pobres no resulta tan clara.

Al respecto, cabe señalar que el proceso de ajuste indudablemente no es la causa principal de la po- 
breza en la región y que la carga impuesta por las medidas de austeridad no ha recaído exclusivamente en los pobres. ${ }^{2}$ De los paŕses examinados, más de la mitad de la población se encontraba ya por debajo del límite de la pobreza antes de que sobreviniera la crisis económica de los años ochenta que, por su parte, aumentó significativamente el número de afectados. Dada la pobreza estructural masiva de los países, los efectos que han tenido los programas de estabilización y ajuste en el aumento del número de pobres en estos paises ban sido insignificantes.

Algunos funcionarios entusiastas suelen dar la impresión de que se hace mucho por los pobres y, a veces, de que los fondos son una suerte de panacea ("el país se encuentra en situación desesperada, pero ahora tenemos el Fondo"). Es más, como los fondos se convierten en el centro de atención, tienden a reemplazar el diálogo político más general sobre los problemas sociales, tanto en el plano interno como con la comunidad internacional. Sin duda alguna, en ellos las cosas se hacen de otra manera: son organizaciones dinámicas, bien dotadas de personal e instaladas en edificios modernos, muy diferentes de las oficinas deterioradas en que usualmente se atienden las cuestiones sociales. También es cierto que se ha concretado un volumen importante de cooperación externa, la que se ha traducido en gastos e inversiones provechosos para los pobres. Sin embargo, hay que recordar que los fondos han desembolsado a lo más de 20 a $30 \mathrm{mi}-$ llones de dólares al año $\mathrm{y}$, en el caso de Bolivia, algunos años quizá el doble de esa suma. Para los fondos más importantes, en el período de máxima actividad esto representa alrededor de 10 dólares al año por cada persona pobre. Aunque no son insignificantes, estas sumas ni siquiera bastan para contrarrestar la reducción del gasto per cápita en los sectores sociales que se ha registrado en muchos países en el último decenio, ni para compensar a la clase obrera por el descenso de los salarios reales.

Por otra parte, los fondos no están llegando hasta los muy pobres, en especial los que viven en comunidades distantes de los centros. Ello se debe en parte a que los indigentes tienen escasa capacidad para elaborar proyectos o defender sus méritos. Este es uno de

\footnotetext{
${ }^{2}$ Además, no hay duda alguna de que algunos programas de estabilización y ajuste han beneficiado a los pobres, incluso a corto plazo. Me refiero en especial a que se ha puesto coto a la inflación desenfrenada, quizá el peor flagelo que haya afectado a los pobres en el último decenio y el factor más desestabilizador desde el punto de vista social y político.
}

los inconvenientes de los programas centrados en la demanda para la generación de proyectos, aparte de que, al menos desde el punto de vista conceptual, son inferiores al optimo para la selección de proyectos y suelen generar proyectos espurios. En general, los proyectos son formulados por personas que tienen experiencia en la materia, y a menudo resulta que éstas no son tan pobres.

Uno de los defectos manifiestos de los fondos es que se concentran en proyectos de infraestructura física cuya función generadora de empleo tiende a pasar por alto a las mujeres. Este sesgo es muy importante, puesto que en estas sociedades las mujeres, junto con los niños, constituyen el grupo más pobre y en gran parte de las familias la mujer es jefe de hogar. Diversos estudios han demostrado que la estructura del consumo de la familia depende de la persona que aporta el ingreso, y las mujeres tienden a administrar el dinero en forma más responsable, es decir, generalmente invierten con prudencia sus entradas en la satisfacción de las necesidades básicas de la familia, sobre todo alimentos y vestuario $\mathrm{y}$, además, tienden a ser más previsoras. Las mujeres han demostrado también ser buenas líderes y poder trabajar en armonía en las empresas populares y en las organizaciones financieras comunitarias.

\section{2. ¿Son los fondos de inversión social la solu- ción?}

Los fondos se concibieron para mejorar rápidamente la situación en que se encontraban algunos pobres, y no para combatir la pobreza estructural de los países. Por esta razón, no puede culpárseles de que no hayan logrado resolver el problema general, lo que por lo demás no les corresponde. Se ha avanzado en el sentido de apartarse de soluciones basadas en la distribución paternalista de alimentos y medicinas y orientarse hacia programas de creación de empleo, pero la finalidad principal nunca fue aumentar en forma permanente los ingresos y el patrimonio de los pobres.

La sola idea de valerse de salarios bajos, iguales o inferiores al salario mínimo (a veces para remunerar las tareas más humildes) como método para seleccionar los empleos y orientarlos hacia los grupos de bajos ingresos, dista mucho de ser un concepto de desarrollo. Evidentemente, es una estrategia de supervivencia que puede aliviar las presiones sociales, pero no sacará a los pobres del nivel de subsistencia. Más aún, para no aumentar las filas de la burocracia, el empleo se ha mantenido deliberadamente como algo transito- 
rio y al margen del aparato estatal. Aunque esto tal vez sea lo más que pueda hacerse dadas las circunstancias, y ciertamente es mejor que cruzarse de brazos, no es un programa para combatir la pobreza.

Es cierto que, por lo general, los proyectos se seleccionan sobre la base de criterios técnicos estandarizados, y esto ha estimulado a que el sector privado y las organizaciones no gubernamentales compitan por la preparación de proyectos, y por el dinero que traen consigo. Sin embargo, no se ha hecho suficiente hincapié en el desarrollo de la comunidad y en la autosuficiencia, que son requisitos indispensables para una verdadera solución, y las contribuciones han solido convertirse en un abierto padrinazgo. Con frecuencia, el beneficio más importante que puede proporcionar un proyecto es enseñar a las comunidades, mediante su participación en la definición, la formulación y la ejecución de un proyecto, que pueden valerse por sí mismas, y crear sentido de responsabilidad y la dignidad que lo acompaña. Al respecto, generalmente se ha dado preferencia al trabajo a contrata en vez de a los sistemas de autoayuda o de alimentos por trabajo, no obstante que a menudo la mano de obra es la única contribución concreta que pueden entregar a un proyecto los miembros de la comunidad. Cuando las comunidades sienten el proyecto como algo propio, participan de mejor grado en su ejecución, el proyecto se lleva a cabo en menor tiempo y hay mayores probabilidades de que se complemente con arreglos relativos a mantenimiento y servicios.

Los programas de inversión de los fondos se han centrado más que nada en la infraestructura económica y social. Se han pasado por alto las actividades directamente productivas, o se les ha asignado escasa prioridad, con lo cual los pobres son más beneficiarios que partícipes del proceso productivo. En los países en que la gran mayoría de la población es pobre, un ataque frontal a la pobreza debe hacer hincapié en la creación de empleos permanentes, y en la producción, la productividad y en consecuencia los ingresos, del sector privado pobre. Pese a que es importante hacerlo, para dar solución al problema de pobreza masiva de los países muy pobres no basta con racionalizar la política macroeconómica y centrar el gasto social en las necesidades básicas. Las medidas de estabilización que requieren los grandes desequilibrios de estas economías dejan escaso margen de maniobra y los presupuestos del sector social son insignificantes (a menudo inferiores al 5\% del PIB) frente a la situación de pobreza de la gran mayoría de la población. Además, la satisfacción de las "necesidades básicas" no resuel- ve el problema de la necesidad también básica que tienen las personas de tener un empleo y un ingreso permanente.

Al respecto, no se ha hecho gran cosa por alterar el patrón de acumulación de capital, el que se encuentra principalmente en manos de los ricos. Salvo raras excepciones, se ha prestado escasa atención a fomentar la formación de capital entre los pobres y a aumentar su productividad (por ejemplo, creando microempresas, mejorando el funcionamiento de los "minifundios", modernizando las actividades del sector informal, etc.). A menudo los pequeños empresarios suelen ser los más afectados por los programas de ajuste estructural, y son ellos también los que han quedado al margen de los beneficios de los programas de compensación. Si los fondos de inversión social no quieren o no pueden satisfacer las necesidades de crédito de las microempresas, es preciso crear algún tipo de mecanismo financiero que lo haga.

Demás está decir que estimular la producción en manos de los pobres es una labor muy difícil y compleja, que constituye la esencia del proceso de desarrollo. Para llevarla a cabo debe hacerse hincapié en la persona, y no tan sólo en el sector social, y tenerse presente una serie de factores extraeconómicos. Más concretamente, se requiere una infinidad de intervenciones del gobierno y de las organizaciones no gubernamentales, de los organismos de cooperación técnica y de las instituciones financieras, así como la realización de gestiones directas y la constancia en la búsqueda de soluciones que son complicadas y a menudo riesgosas. Además, la generación y el seguimiento de una amplia variedad de proyectos productivos pequeños entraña mayores costos administrativos. En el intento por lograr resultados inmediatos, los fondos generalmente han optado por el camino más fácil, esto es, financiar proyectos de infraestructura y de asistencia.

\section{3. ¿Cómo asegurar la sustentabilidad de los pro- yectos?}

Uno de los principales puntos débiles del funcionamiento de los fondos de inversión social es la sustentabilidad de los proyectos. El quid de la cuestión es el hecho de que los fondos son mecanismos transitorios, pero las obras a que dan lugar pretenden ser permanentes. Muchos proyectos tienen componentes de servicios operacionales, y todos ellos requieren mantenimiento. En realidad, a menudo es más apremiante mantener los proyectos que realizar otros nuevos. Por regla general, 
el costo de las operaciones de mantenimiento es muy alto en relación con los beneficios.

Sin embargo, los fondos son por naturaleza ejecutores y no planificadores, y suelen no prestar la debida atención a gastos periódicos futuros. Además, las operaciones de mantenimiento no tienen muchos atractivos: no hay ceremonias inaugurales ni rituales de corte de cintas. Es más práctico participar en proyectos claros y concretos y dejar a otros la engorrosa tarea de ocuparse del mantenimiento. Por otra parte, los gastos de mantenimiento son elevados y a lo largo de los años pueden sumar cifras superiores al costo inicial del proyecto.

No hay duda alguna de que el suministro de servicios de mantenimiento y de apoyo operativo a menudo plantea serias dificultades. Sin embargo, para que los proyectos entreguen los beneficios esperados, e incluso para que sobrevivan, es preciso abordar el problema de frente. Hay que partir de la base de que armar la infraestructura es tan sólo la primera fase de un proyecto. Esto resulta aún más evidente en el caso de proyectos de servicios básicos, como los de salud y educación. Evidentemente, salvo que puedan adoptarse medidas concretas para financiar la totalidad del proyecto, incluido su componente operativo, éste ni siquiera debería iniciarse.

En la práctica, muchos de los proyectos ejecutados por los fondos en la esfera social consisten en la rehabilitación de instalaciones reales, que ya cuentan con presupuestos estatales (por ejemplo, una escuela existente). En este caso, los fondos pueden llevar a cabo proyectos de infraestructura social sin tener que depender de asignaciones presupuestarias adicionales. A veces, se han creado programas estatales paralelos para prestar apoyo institucional y ampliar los servicios educacionales, de salud $\mathbf{u}$ otros servicios asistenciales. Con frecuencia se ha justificado el financiamiento tanto interno como externo argumentando que, en realidad, se trata de inversiones en capital humano, con la esperanza de que con el tiempo se produzca un aumento de las entradas fiscales que contrarreste los que se consideran déficit presupuestarios de carácter transitorio. Los fondos de inversión social pueden, entonces, desempeñar la función complementaria de proporcionar infraestructura a los servicios ampliados.

Téricamente, lo apropiado es hacer responsables a los beneficiarios de los costos periódicos pertinentes, exigiendo el pago de derechos de uso, los que pueden ser recaudados, por ejemplo, por los municipios. Ello entraña concebir un programa de gravámenes y proporcionar apoyo institucional. En la práctica, cuan- do se trata de comunidades pobres, los sistemas de derechos de uso son difíciles de aplicar y suelen ser arbitrarios.

Cabe señalar que todas estas medidas para asegurar la continuidad operativa parten de la base de que haya una estrecha coordinación institucional entre los fondos de inversión social y los ministerios sectoriales pertinentes, los municipios y otros organismos estatales. Obviamente habría que integrar los proyectos dentro de los planes y presupuestos sectoriales del gobierno.

Finalmente, siempre que ello sea posible, quizá la mejor manera de asegurar que no se desatiendan los componentes operacionales y de mantenimiento de los proyectos es hacer participar en ellos a las propias comunidades. Una asociación de ciudades o una organización no gubernamental que haya formulado un proyecto o participado en su ejecución puede ser decisiva para asegurar su sustentabilidad. Sin embargo, para garantizar que las comunidades asuman la responsabilidad de los proyectos se necesita bastante tiempo y esfuerzos y a menudo se ha estimado que la tarea escapa a la esfera de acción de los fondos.

\section{El papel de los fondos en relación con los ministerios sectoriales pertinentes}

Una de las razones principales que justifican la creación de mecanismos nuevos para combatir la pobreza es que, desde el punto de vista institucional, los ministerios involucrados carecen de capacidad para llevar a cabo los proyectos y administrar eficazmente grandes programas de emergencia. No por azar esta hipótesis coincide con la tendencia actual a reducir la esfera de acción de los gobiernos en relación con aquélla del sector privado y a considerar que la función planificadora del gobierno es contraproducente.

Se sostiene que la manera de organizar con rapidez una obra importante es valerse de mecanismos similares a los del sector privado, en vez de tratar de reformar las burocracias tradicionales, que son ineficientes y a veces venales. En la práctica, se ha optado por crear instituciones estatales noveles, en gran medida libres de actuar como empresas privadas pero que no persiguen fines de lucro sino objetivos sociales.

La idea es garantizar una corriente constante de recursos financieros con el establecimiento de vías que soslayen el débil aparato estatal. Sin embargo, poco a poco se ha llegado a mirar estas vías nuevas no como de emergencia, sino como soluciones formales que se apartan del campo de acción de los gobiernos y que 
pueden debilitar todavía más las vías de acción ordjnarias. Toda vez que los fondos sociales reemplazan el conducto regular, se tiende a menoscabar las instituciones existentes y a ceder a la tentación de usurpar funciones que corresponden a los ministerios del sector, como la formulación de la política social.

También se ha expresado alguna preocupación por el hecho de que los fondos puedan desviar recursos de los presupuestos ministeriales. Ello rara vez ha ocurrido, puesto que los fondos han contado con amplio financiamiento de fuentes externas y en la mayoría de los casos el aporte de los gobiernos se ha utilizado como capital inicial para poner en marcha las actividades o para otorgar anticipos con cargo al financiamiento que se está negociando. Por otra parte, hasta ahora pareciera que no se están desviando recursos provenientes de financiamiento externo que de lo contrario habrían podido destinarse a otros proyectos sociales. Todo indica que la mayor parte del financiamiento externo ha sido adicional.

No obstante que las operaciones de algunos fondos se han visto obstaculizadas por demoras en el acceso al financiamiento externo, en general, parece que la limitación determinante para los países no son los recursos; más bien parece serlo la capacidad de los organismos estatales de absorber recursos externos y transformarlos en inversiones. Paradójicamente, el presupuesto operativo de los ministerios del sector social suele ser tan exiguo que cubre apenas los gastos en sueldos y en insumos para satisfacer necesidades básicas.

Finalmente, cabe señalar que la creación de una dependencia separada para proporcionar servicios estatales a los pobres tiende a situaria al margen del resto de la acción del gobierno: una política y programa para los pobres, y otra para el resto de la economía. Sin embargo, la política estatal es necesariamente una; entre la política social y la política económica no puede haber dicotomía, subordinación ni correlatividad. La conocida excusa de que "primero hay que poner la casa en orden, después avanzar hacia una trayectoria de crecimiento sostenible y finalmente atender a las necesidades sociales" carece de validez y, en la situación actual, no resulta viable. Centrar la atención en el bienestar y en los ingresos de los pobres debe ser parte integrante de una política global de desarrollo economico.

Evidentemente, el Estado tiene un papel decisivo en la formulación y la aplicación de esta política. Al gobierno, por definición, le corresponde una función de redistribución del ingreso (que es particularmente importante en América Latina, donde la distribución del ingreso es extremadamente asimétrica), la facultad de establecer la política de precios y salarios, el deber de proporcionar servicios básicos de educación y de salud y de establecer una red de seguridad social, y una misión que cumplir en la creación del clima necesario para que el sector privado se desarrolle en forma vigorosa y equitativa. Todas estas responsabilidades son indelegables. Como es natural, la creación de una institución capaz de canalizar con eficiencia los recursos externos hacia los pobres no exime al Estado de su obligación de llevar a cabo programas socioeconómicos urgentes; ni lo libera de la necesidad de reestructurar el aparato estatal mismo.

\section{La politización de los fondos}

Uno de los principales méritos de los fondos ha sido el vigoroso apoyo político que han recibido. Sin embargo, la vinculación estrecha que han mantenido con altas autoridades políticas ha solido dar lugar a crecientes presiones para politizar sus operaciones en beneficio del partido en el poder.

Todos los fondos de inversión social sostienen que están al margen de la política partidista, esto es, que al distribuir los recursos de los proyectos tratan de tener en cuenta consideraciones de eficiencia y de no favorecer a un grupo determinado. Sin embargo, como alivian las presiones sociales y amortiguan los efectos negativos de los programas de estabilización y ajuste, no pueden menos que proporcionar beneficios políticos al presidente en ejercicio y al partido que representa.

En un intento de hacer atractivos los programas de austeridad, los fondos han hecho hincapié en el logro de resultados inmediatos y manifiestos, que demuestren que se está haciendo algo por los pobres. En consecuencia, es fácil comprender que en época de elecciones un fondo dispuesto a entregar dinero es una ganga política muy tentadora. Sin embargo, que un fondo ceda a las presiones para convertirlo en pieza de la maquinaria política partidista y evolucione hacia un modelo de padrinazgo equivale a asestar un rudo golpe a su eficacia operativa y a la imagen que de él tienen los donantes extranjeros, y probablemente sería el "beso de la muerte" si el gobierno en el poder perdiera las elecciones.

Teóricamente, una de las maneras de garantizar que los fondos no se vean tentados a desviarse de su función de servicio y puedan sobrevivir más allá de un ciclo electoral es que sean administrados por directo- 
rios bipartidistas. Otra medida que podría adoptarse para despolitizar la imagen de los fondos sería limitar la propaganda sobre sus Iogros a simples boletines informativos y solicitar la divulgación de todas sus operaciones financieras. Sin embargo, estas sugerencias resultan pueriles puesto que los gobiernos, por naturaleza, adoptan medidas políticas que dan dividendos políticos. Tal vez lo más que pueda pretenderse es que los fondos de inversión social se mantengan bajo la dirección de autoridades no proselitistas, cuyo prestigio personal sea tal que puedan resistir las presiones de sus propios gobiernos para politizar las operaciones del fondo y decirle "no" a los ministerios sectoriales pertinentes cuando un proyecto no se justifique.

A menudo, la participación activa de las comunidades en los proyectos de los fondos puede contrarrestar el padrinazgo de corte político. Una comunidad que haya tomado conciencia de la materialización de su propio potencial cívico no podrá ser manipulada fácilmente. Sin embargo, la línea demarcatoria entre promover la participación de la comunidad y estimular un control paternalista de ella es muy tenue. Por ejemplo, en un intento por aumentar su eficacia, los fondos de inversión social han procurado descentralizar la toma de decisiones radicándola en el gobierno local, y proporcionar recursos a los municipios. No hay duda de que esto es positivo, siempre que no pretenda fortalecer el control político de los municipios por los alcaldes ni desalentar el surgimiento de líderes comunitarios espontáneos y de organizaciones comunitarias independientes.

\section{Vinculación de los fondos con las organizacio- nes no gubernamentales}

Las organizaciones benéficas y otras organizaciones no gubernamentales han mantenido una larga tradición de ayuda a las comunidades pobres para aumentar su bienestar. En especial, los grupos de iglesia prestan asistencia en regiones aisladas a las que no llegan o no pueden llegar los ministerios pertinentes. Asimismo, por conducto de las organizaciones no gubernamentales se ha concretado mucha cooperacion internacional entre personas (people-to-people) en diversos campos. Por definición, estas organizaciones actúan en el ámbito de la labor cívica y, en consecuencia, abordan los problemas sociales desde un ángulo diferente de aquél de los gobiernos, y se rigen por normas distintas. Las organizaciones no gubernamentales generalmente hacen hincapié en la naturaleza estructural de la pobreza y de la injusticia social que la origina. Porque están más próximas a las comunidades locales, tienen aguda conciencia del costo de las políticas de estabilización y ajuste que recae sobre los pobres y acogen con recelo los ofrecimientos de un fondo estatal de inversión, naciente y de duración incierta, que comienza a invadir un campo que antes les estaba reservado. A ta inversa, algunos funcionarios de gobierno miran con desconfianza e incluso con hostilidad la autonomía institucional y financiera de las organizaciones no gubernamentales y su creciente esfera de acción. Sin embargo, son precisamente su independencia del control gubernamental y su clara predisposición en favor de los pobres to que atrae a los donantes externos, a quienes les interesa más ayudar a éstos que prestar asistencia a los gobiernos.

Es cierto que el antagonismo natural de las organizaciones no gubernamentales al control del gobierno a menudo las lleva a actuar sin coordinación y con desigual eficacia. Con todo, las mejores han demostrado ser buenas intermediarias para la formulación y ejecución de proyectos pequeños y para asegurarse de que los recursos lleguen basta quienes más los necesitan, y esto ha sido un importante hallazgo de los fondos de inversión social. En especial, éstos han aprovechado la experiencia de las organizaciones no gubernamentales en pequeños proyectos de servicios de salud. Estas organizaciones actúan con flexibilidad y pragmatismo y sirven de catalizadoras para estimular la participación de las bases en las comunidades beneficiadas. Sin embargo, su forma de operar no es propicia para la expansión acelerada de las actividades, de modo que sólo pueden absorber un volumen limitado de recursos. Por otra parte, corren el riesgo de que la excesiva abundancia de financiamiento las lleve a depender de las autoridades de gobierno y de otros intereses, a subordinarse a ellos o a pervertir su altruismo habitual, convirtiéndose en simples empresas con fines de lucro.

Aunque las organizaciones no gubernamentales se han usado con éxito para ejecutar proyectos, no se les ha permitido participar en los aspectos conceptuales o de organización de los fondos, por lo que suelen quejarse de que no se sienten representadas. No hay duda alguna de que estas organizaciones tienen una función que cumplir en la formulación de proyectos y algo que decir respecto de las prioridades fijadas, pero obviamente la definición de la política económica o social del Estado está fuera de su esfera de competencia, como también lo están la política partidista o la promoción de intereses foráneos. Su verdadera función está en el ámbito de la labor cívica, que es ajeno al del Esta- 
do. Por otra parte, los gobiernos pueden y deben crear las condiciones y estimular el desarrollo de dicha labor, pero no deberían pretender fiscalizar a las comunidades, ni exigir subordinación. Al ocuparse de los problemas ć́vicos y tratar con las organizaciones comunitarias, los gobiernos necesariamente deben poner freno a su naturaleza política. Sin embargo, tanto a los gobiernos como a las organizaciones no gubernamentales les conviene mucho establecer un diálogo permanente para coordinar las actividades, y los fondos de inversión social han comenzado a colmar este vacío.

\section{La cooperación externa: Lestímulo o sustitu- to del esfuerzo interno?}

Al eludir los cauces estatales ordinarios, el financiamiento externo proporcionado a los fondos de inversión social ha logrado satisfacer con rapidez un elevado número de necesidades importantes. El mecanismo es eficaz, por cuanto puede realmente beneficiar a los pobres y ser razonablemente eficiente; complace a los donantes y los gobiemos receptores obtienen algún alivio de las presiones sociales, así como gran parte del reconocimiento por las realizaciones. Sin embargo, a veces la cooperación externa no ha hecho más que compensar la falta de esfuerzo interno e incluso la ausencia de voluntad política.

¿Hasta cuándo pueden los gobiernos seguir dependiendo casi exclusivamente de dádivas externas para aliviar situaciones sociales de carácter crítico, sin asumir plenamente la responsabilidad que les corresponde en la lucha contra la pobreza y en el fomento del desarrollo equitativo? No hay duda de que si no se dispusiera de recursos externos las actividades de varios fondos se paralizarían. La excusa de que "el Fisco carece de recursos para invertir en proyectos sociales" indica el grado de dependencia externa a que han llegado algunos países, dependencia que se exacerbó durante la prolongada recesión de los años ochenta. Sin duda alguna, cuando se trata de problemas tan propios como la pobreza crítica no conviene depender de la intervención extranjera, la que sólo puede aceptarse como medida de emergencia.

\section{Los fondos de emergencla en contraposición a las instituciones de inversión permanentes}

Mucho se discute si los fondos deberían seguir siendo mecanismos transitorios para lograr efectos inmediatos en una coyuntura crítica, o evolucionar hasta convertirse en órganos permanentes dotados de propiedades y funciones de largo plazo.
Desde luego, hay que reconocer que la duración que se asigna usualmente a los fondos de emergencia (tres a cuatro años) es demasiado limitada. Para echar a andar un fondo en lo que hace a sus aspectos institucional y operativo se necesita un año o más, y los organismos financieros externos a menudo tardan aún más en aprobar los planes de financiamiento.

Además, hay otras razones de orden práctico para prolongar la vida de los fondos. No puede negarse que se ha reunido personal competente y sería una lástima dispersarlo. Asimismo, los fondos de emergencia benefician a los pobres, y no se puede simplemente abandonar esta línea de acción. Los fondos han demostrado ser un buen medio para canalizar la ayuda externa y la cooperación, y la forma en que han orientado sus actividades ha apaciguado el temor de los donantes de que se los utilice tan sólo para financiár o aumentar la nómina estatal.

Al mismo tiempo, no se han alcanzado los objetivos macroeconómicos que dieron lugar a la creación de los mecanismos compensatorios. El ajuste estructural dista mucho de haberse terminado, el camino al crecimiento no se ha consolidado y en varios países el proceso de estabilización es precario. Sobran razones, como sobraban hace algunos años, para atender a las necesidades de los pobres y mitigar las presiones sociales. Además, no se han reestructurado los ministerios sectoriales que ordinariamente se ocupan de las cuestiones sociales y no está claro que hayan aumentado su capacidad de ayudar a los diversos sectores sociales o de cumplir las funciones de distribución del ingreso que realmente les corresponden.

Sin embargo, hay argumentos que apuntan en sentido contrario a la prolongación de los fondos. A medida que éstos se desarrollan, ven debilitarse su vigor y su mística originales y tienden a convertirse en una burocracia más. Como no están sujetos a los sistemas de control de la administración pública y de los procedimentos de adquisiciones, siempre existe el peligro de que se infiltren en ellos el compadrazgo e incluso la corrupción. Además, a medida que se revelan las ventajas políticas que pueden obtenerse de un fondo, tienden a acumularse presiones favorables a su politización.

En todo caso, sean cuales fueren los aspectos conceptuales, una vez que estas instituciones se consolidan se produce una tendencia natural a perpetuarlas, como sucede en todas las burocracias. Todo indica que los fondos no han de desaparecer.

$Y$ si se intenta convertirlos en instituciones permanentes, hay que encontrarles un nicho adecuado. Los 
fondos de inversión social podrían ampliar su alcance y centrarse derechamente en el alivio de la pobreza. Si se resolviera montar un programa general de desarollo en torno a la lucha contra la pobreza, ciertamente se necesitarían instituciones permanentes, ya que los mecanismos de carácter transitorio no se prestan bien para hacer frente a la pobreza estructural, ni puede hacérseles responsables de ello. En definitiva, el papel que desempeñen los fondos dependerá de las decisiones que se adopten en el plano nacional en materia de política socioeconómica.

\section{Algunas cuestiones macroeconómicas}

En el financiamiento proporcionado a los fondos de inversión social de los países examinados, las remuneraciones absorben aproximadamente un tercio del costo total de los proyectos, y los materiales locales más de la mitad. Sólo una pequeña parte del financiamiento externo se destina a importaciones. Así pues, las divisas provenientes del financiamiento externo sirven para apoyar la balanza de pagos de los países.

Sin embargo, a medida que las divisas se convierten en moneda local y se utilizan para adquirir bienes y servicios, se generan rondas sucesivas de ingresos y gastos que, a su vez, dan lugar a importaciones adicionales. Por otro lado, tarde o temprano los proyectos exitosos generan una corriente de producción e ingresos, y por ende una nueva corriente de importaciones. Estas importaciones adicionales suelen tener efectos negativos en la balanza de pagos, porque los proyectos que llevan a cabo los fondos de inversión social no son del tipo generador de exportaciones.

En suma, aunque tal vez más de un $90 \%$ de la ronda inicial de financiamiento externo vaya a apoyar la balanza de pagos, la estimación de los efectos que producen los gastos originales a medida que se abren paso a través de la economía indican que las importaciones generadas en el proceso absorben rápidamente gran parte de las divisas disponibles.

Al mismo tiempo, el mayor financiamiento monetario a que da lugar la transferencia de recursos externos estimulará la demanda y seguramente ejercerá presión sobre los precios. Su efecto en el ingreso y en las importaciones tiende a ser de corta duración, ya que en su mayor parte se extinguirá dentro de un año debido a la marcada propensión a importar. ${ }^{3}$

${ }_{3}^{3}$ Cabe señalar que, con excepción del Fondo Social de Emergencia de Bolivia, los efectos macroconómicos de los fondos de inversión social en el conjunto de la economía de cada país son insigni-
Cabría preguntarse qué proporción del ingreso generado por los fondos es aprovechada por los pobres. Incluso en el optimista supuesto de que un tercio de los nuevos ingresos generados por todas estas transacciones se utilice para contratar trabajadores pobres, más de dos tercios del ingreso total generado por los fondos de inversión social terminará en manos de importadores, empresarios y funcionarios remunerados, po$\cos$ de los cuales son pobres. En consecuencia, por extraño que parezca, en los países en que la distribución del ingreso es extremadamente asimétrica, gran parte de los beneficios que emanan de los programas generadores de ingreso, incluso los que son subvenciones directas, tienden a favorecer a los asalariados más adinerados (aunque no en una proporción lo suficientemente grande como para concentrar aún más el ingreso).

\section{0. ¿Puede una red de seguridad de emergencia destinada a unos pocos conducir a una estra- tegla amplia para combatir la pobreza crítica?}

Tras una prolongada recesion, la más grave registrada desde los años treinta, los gobiernos latinoamericanos tuvieron que introducir penosos programas de ajuste para "poner la casa en orden" y lograr algún grado de estabilidad. Además, aplicaron políticas de ajuste estructural basadas en una mayor orientación de mercado, más actividad del sector privado y más apertura al mundo exterior.

$\mathrm{Al}$ impartir este rumbo común a la política económica, ha quedado de manifiesto que, dentro de un marco político democrático, el modelo centrado en el mercado es incompatible con la pobreza masiva. En todo caso, la "estabilización en medio de la pobreza" y las "elecciones en medio de la miseria" no son por cierto metas deseables.

Factores económicos y presiones políticas - de hecho exacerbadas por el surgimiento de regímenes democráticos - han sacudido la apatía habitual respec-

ficantes. En el caso del Fondo mencionado, en sus cuatro años de funcionamiento los desembolsos constituyeron alrededor de un $16 \%$ del total de las inversiones del sector público. Se proporcionó empleo directo de carácter transitorio a un promedio de 19000 trabajadores, y se generó empleo adicional conforme al crecimiento de la economía (21 500 puestos de trabajo adicionales). Estimaciones del Fondo indican que durante ese período el PIB aumentó un promedio de 0.6\%. De acuerdo con una estimación del PNUD, en 1990 el ptB se elevó más del $1 \%$ como resultado de las actividades de] Fondo, pero la reactivación de la economía fue de corta duración puesto que en 1991 el incremento del PIB fue de sólo $0.3 \%$. Diversas estimaciones revelan que la inflación aumentó menos del $2 \%$. 
to de la situación crítica de los pobres y han llevado a los gobiernos a buscar maneras de aflojar las tensiones sociales. La atención de los gobiernos se está desplazando de las políticas de eficiencia económica a los problemas de pobreza. Al mismo tiempo, las organizaciones financieras internacionales y algunos países donantes, cada vez más conscientes de los críticos problemas sociales que aquejan a América Latina y preocupados de la supervivencia de los programas de ajuste estructural que están auspiciando, también han reconocido que es urgente mejorar la situación de los sectores de la población que se han visto más afectados por la crisis y por el propio proceso de ajuste. En realidad, su influencia ha desempeñado un papel catalizador en la organización y puesta en marcha de los programas para aliviar la pobreza. Así pues, el hecho de que hayan coincidido la preocupación interna y externa, unido a la posibilidad de obtener donaciones y créditos en divisas en condiciones de favor, ha llevado a varios países pobres de la región a crear fondos de inversión social de emergencia.

Tal vez el logro principal de los fondos haya sido demostrar cuánto es posible hacer, y cuán rápido, cuando existe la voluntad política necesaria. $Y$ como corolario, de ello parece desprenderse que la pobreza es consecuencia más bien de la falta de voluntad política que de la escasez de recursos, y que es posible romper el círculo vicioso de falta de confianza de los donantes e incompetencia burocrática.

No hay duda alguna de que traer el problema de la pobreza al primer plano y mostrar que los gobiernos comienzan a ocuparse del problema es un avance importante. Sin embargo, si la voluntad política y la asistencia externa pueden desencadenar una reacción tan rápida, ¿no podría quizá ampliarse el campo de ac- ción de los fondos de emergencia o crear programas nuevos que puedan centrarse en todo el abismante problema global de pobreza de los países latinoamericanos? Al parecer, están dadas las condiciones para que los gobiernos avancen en esa dirección mediante la introducción de programas generales, a largo plazo, para combatir la pobreza, no sólo en aras de la justicia social y de la conveniencia política, sino como condición de la viabilidad económica y del crecimiento de los países.

La ideología y las complicaciones de la confrontación este-oeste son cosa del pasado. Lo que queda en definitiva no es un sistema capitalista que haya que perfeccionar sino el antiguo dilema social y económico de la mayoría de las naciones latinoamericanas: grandes masas pauperizadas que participan poco y se benefician menos del crecimiento económico de sus países. La solución de este enorme problema exige, ante todo, la participación de los propios pobres. El Estado también tendrá que desempeñar un papel importante: no puede soslayarlo. En consecuencia, será preciso adoptar medidas decisivas para modernizar el Estado, y hacerlo menos frondoso y más eficaz. Y, por ultimo, para aplicar un programa general de lucha contra la pobreza de los países muy pobres se necesitará una fuerte dosis de ayuda financiera externa, así como el respaldo político de la comunidad internacional.

Pese a sus numetosos inconvenientes, los fondos de inversión social están creando tecnología para la acción social. Su propia existencia puede abrir el camino hacia la adopción de políticas y programas sociales y de reformas institucionales de carácter más amplio.

(Traducido del inglés) 